\title{
Los magistrados también hacen política. Las disputas por los espacios en el poder judicial de la nación*
}

\author{
Judges Also Do Politics. \\ Disputes for Spots in the National Judicial Branch
}

Os magistrados também fazem política.

A disputa pelos espaços no poder judiciário do país

Juan José Nardi**

\section{RESUMEN}

En este artículo se analiza la relación entre jueces y política en

Palabras clave:

el marco de los concursos realizados por el Consejo de la MagisEstado, familia tratura de la Nación y en los diferentes nombramientos y ascensos realizados por los magistrados en los juzgados y vocalías a su cargo. Para lograrlo, se reconstruyen las dinámicas cotidianas judicial, jueces, poder judicial, política. de interacción que adquiere el tipo de disputas políticas que se pretenden analizar, así como también las estrategias y las alianzas construidas para cumplir con sus objetivos. En este aspecto, las redes de pertenencia a tener en cuenta son las que se articulan alrededor de las asociaciones que representan corporativamente a los magistrados. El objetivo es mostrar que la mencionada relación no solo se expresa, en el plano jurisdiccional, como habitualmente se lo plantea, sino también en los espacios en donde los magistrados se desempeñan tanto como jefes administrativos de la oficina judicial, así como consejeros o como postulantes a los concursos mencionados. Esto supone poner en discusión algunas de las categorías utilizadas en los estudios más importantes sobre el tema para poder hacer un aporte que

\footnotetext{
* Este artículo se desarrolló en el marco del proyecto UBACyT "Política y poder judicial. Redes, trayectorias e instituciones en la justicia nacional y federal", con sede en el Instituto de Investigaciones Gino Germani, Facultad de Ciencias Sociales, Universidad de Buenos Aires.

** Magíster en Investigación en Ciencias Sociales, Universidad de Buenos Aires (UBA). E-mail: juanjnardi@gmail.com
} 
a partir de la especificidad del caso y, del relevamiento empírico realizado, se logre una mayor comprensión del fenómeno.

\begin{abstract}
This paper analyses the relationship between judges and politics in the context of the competitions on merit and exams held by the Judiciary National Council and in the various appointments and promotions made by judges in the courts and offices they lead. To achieve this, it reconstructs the daily dynamics of interaction acquired by the type of political dispute to be analyzed, as well the strategies and alliances built to meet the objectives. In this regard, the membership networks to be taken into account are those that are structured around associations that corporately represent the judges. The aim is to show that the abovementioned relationship is not only expressed at the jurisdictional level, as usually suggested, but also in areas where judges serve as administrative heads of the judicial office, councilors or candidates to competitions and exams on merit. This involves a discussion of some of the categories used in the most important studies on the topic in order to contribute to and better understand the phenomenon based on the specificity of the case and the empirical survey carried out.
\end{abstract}

\section{RESUMO}

Neste artigo é analisada a relação entre os juízes e a política no âmbito dos concursos realizados pelo Conselho da Magistratura da nação argentina e nas diferentes nomeações e promoções feitas pelos magistrados nos juizados e órgãos colegiados sob sua responsabilidade. Para tanto, são reconstruídas as dinâmicas diárias de interação que adquire o tipo de disputas políticas que se pretende analisar, assim como as estratégias e alianças construídas para cumprir seus objetivos. Neste aspecto, as redes de pertencimento a serem levadas em conta são as que se articulam em torno das associações que representam corporativamente os magistrados. O objetivo é mostrar que tal relação não se expressa apenas no nível jurisdicional, como habitualmente se propõe, mas também nos espaços onde os magistrados desempenham cargos tanto de chefias administrativas do escritório judicial, quanto de conselheiros ou candidatos aos concursos acima mencionados. Isto significa colocar em discussão algumas das categorias utilizadas nos estudos mais importantes sobre o assunto, a fim de fazer uma contribuição que, baseada na especificidade do caso e na pesquisa empírica realizada, alcance uma maior compreensão do fenômeno.
Keywords: State, patronaje appointments, judges, judiciary, politics.

Palavras-chave: Estado, família judicial, juízes, poder judiciário, política. 


\section{Introducción}

En un metálogo, Gregory Bateson (1998) dialoga con su hija sobre el orden y el desorden. La pregunta que ella le hacía era por qué las personas no presentan discrepancias cuando se refieren a un revoltijo pero no se ponen de acuerdo sobre lo que está ordenado. El pensador anglosajón le sugiere a Cathy que teniendo en cuenta su escritorio le dijera cuál consideraba que era el lugar correcto para sus pinturitas. La niña señala un lugar, a lo que su interlocutor le repregunta qué sucedería si las mueve un poco hacia la izquierda y las gira media vuelta en sentido antihorario. Ella le responde que estarían fuera de lugar.

Inmediatamente, Bateson le sugiere que ella misma ha dado la respuesta a su pregunta. Hay muy pocos lugares que asocia como correctos para sus pinturitas, pero muchos que se acercan al desorden. Como corolario, afirma que si bien existe una manera ordenada de hacer las cosas, por diversas razones, estas últimas siempre se encaminarán hacia el revoltijo y la mixtura.

Analogía mediante nuestro juez nacional o federal ${ }^{3}$, cualquiera sea la instancia en que se desempeñe, comparte ciertas características con las pinturitas de Cathy. Sus márgenes de acción están tan acotados que cualquier práctica que se corra de lo prestablecido nos lleva a juzgarla con distintas intensidades como fuera de lugar. Esto se debe, en gran medida, a nuestra concepción napoleónica del magistrado como boca de la ley; es él y su conciencia quien decide en función de los hechos y a través de los anteojos de la ley. Nadie lo ayuda, ni tampoco lo necesita. A su alrededor, las personas que lo asisten se hacen cargo de las tareas administrativas que lo apartarían de su tarea de juzgar y que son necesarias para la tramitación del expediente. Esto es así porque lo establece el Código Procesal Civil y Comercial de la Nación en sus artículos 34, 35 y 36, y porque su secretario da fe de las acciones realizadas por el magistrado.

La mal llamada justicia nacional solo tiene jurisdicción en la Ciudad Autónoma de Buenos Aires (CABA) y no tiene competencia federal, aunque depende de la CSJN y por ende es parte del Estado nacional. En este sentido, si bien en la CABA también existen fueros federales no deben confundirse los jueces nacionales con los jueces federales ya que tratan materias diferentes. 
Como es posible intuir, el estricto apego al orden de las cosas propuesto por el código no es la regla. Así, por ejemplo, tenemos empleados redactando proyectos de sentencias y jueces ausentes en audiencias en las que deberían estar, por citar solo algunos de los casos más comunes. Entonces, existe cierta tolerancia con relación a qué práctica de los magistrados es definida como fuera de lugar. En los hechos, por ejemplo, se acepta un acto de delegación por parte de los magistrados hacia los funcionarios y empleados que trabajan con él.

Es importante señalar que no es solo en estos aspectos en donde se evalúa la práctica de los jueces como desplazada del espacio que le corresponde. Una muy importante, y que es sobre la que me voy a detener en este artículo, es la asociada a la práctica política de los magistrados. En su artículo 9 el decreto Ley No 1285/1958, y sus modificatorias, referido a la organización de la justicia nacional sostiene entre otras cosas que "no podrán estar afiliados a partidos o agrupaciones políticas, ni actuar en política”.

La prohibición está asociada a posibles influencias en el contenido de los fallos, sentencias y resoluciones de los magistrados. En este contexto, el poder de los jueces,y su supremacía sobre el resto de las personas con las que se relaciona es legítimo si actúan de acuerdo con el derecho.

Las sentencias de los magistrados son consideradas ilegítimas y politizadas cuando se cree que no actúan de acuerdo con el derecho, por presión o convicción, en donde sus trayectorias, sus vinculaciones con la política con anterioridad o posterioridad a sus nombramientos pueden ser indicadores de los motivos de la acción.

En análisis de estas características, la política ilegítima es la partidaria y comúnmente se expresa en los distintos elencos políticos de los oficialismos de turno. El juez que es señalado por actuar políticamente de este modo es considerado fuera de lugar y, por lo tanto, su accionar es contrario a los principios republicanos.

No considero que este tipo de situaciones no puedan darse, sino que discuto que sea la única forma de plantear el problema. En primer lugar, porque lo jurisdiccional es solo una de las dimensiones para analizar y, en segundo lugar, porque es incorrecto asumir que las únicas acciones políticas que se les puede adjudicar a los jueces se en- 
cuentran asociadas a convalidar los intereses del Poder Ejecutivo Nacional (PEN) (u otros poderes fácticos). Esta idea supone desestimar la existencia de intereses propios de los magistrados en tanto grupo.

Existen posiciones que avanzan con el análisis de la situación planteada en el párrafo anterior a partir de la idea de independencia interna del Poder Judicial de la Nación (PJN). En efecto, si lo dicho anteriormente refiere a la afectación de la independencia judicial por parte de poderes externos a la institución, el mencionado concepto refiere a la presión que un magistrado puede recibir de sus pares o superiores jerárquicos.

Más allá de lo dicho, hay que ser cuidadosos con esta distinción. Si bien, por fines analíticos, diferenciar entre independencia interna de independencia externa puede ser de utilidad, es difícil establecer objetivamente cuándo una presión interna no es solo una intermediación de voluntades externas al PJN.

Entonces, cuánto aclara - o confunde-con los fines de comprender la acción política hacia el interior del PJN dejar asociada esta práctica a la idea de independencia en cualquiera de sus formas es una pregunta que vale la pena formular para poder avanzar en un sentido distinto a lo ya realizado. Qué características asumiría entonces el análisis de las prácticas políticas en esta institución si no las pasáramos por el tamiz de la república.

Con el problema así formulado es importante llevar la mirada a la dimensión del autogobierno del PJN. Este escenario se vio especialmente modificado luego de la reforma constitucional de 1994, ya que a partir de la puesta en funcionamiento del Consejo de la Magistratura de la Nación los magistrados comenzaron a tener un rol en la selección, la disciplina y el enjuiciamiento de sus pares que antes estaba reservado para los otros poderes del Estado ${ }^{4}$.

Quiero avanzar, entonces, en la comprensión de las prácticas políticas llevadas adelante por los mencionados actores tanto en ese ámbito

Podemos decir lo mismo respecto de la administración del presupuesto del PJN, aunque en este caso las funciones fueron transferidas desde la CSJN. Este tema ha generado extensas discusiones por lo que remito al trabajo de Ábalos (2012) para profundizarlo. 
como en el que desempeñan cotidianamente sus funciones. Lo haré a partir del análisis de una serie de entrevistas en profundidad a magistrados nacionales y federales pertenecientes al PJN, además de un conjunto de observaciones sistemáticas de las reuniones de la Comisión de Selección y Escuela Judicial del Consejo de la Magistratura.

Para esto, no me voy a detener solamente en los posibles procesos de interacción con los otros poderes del Estado, sino también en cómo se expresan las mencionadas prácticas en las relaciones con sus pares, observando cuestiones específicas de su ejercicio profesional, además de otras instancias de vinculación, como puede ser la Asociación de Magistrados y Funcionarios de la Justicia Nacional (AMFJN) y la Asociación de Jueces Federales (AJUFE) 5 . En términos exploratorios, mi hipótesis es que no se logra una comprensión acabada de las prácticas políticas de los magistrados si no se integra al análisis sus vínculos con los otros poderes del estado, los procesos de negociación y disputas que se establecen entre los grupos a los que pertenecen los jueces.

Así, en el próximo apartado voy a presentar las principales aristas de la discusión académica en torno a la relación entre jueces y política; en el tercer apartado voy a desarrollar los criterios vinculados al recorte del objeto y la presentación de las técnicas utilizadas para recolectar la información; en el cuarto apartado voy a comentar los principales hallazgos del relevamiento empírico; y en el último voy a poner en discusión de qué forma la información relevada permite una aproximación crítica a ciertos supuestos aceptados por la bibliografía comentada y que puede servir de punto de partida para futuras investigaciones.

\section{Jueces y política. Distintas aproximaciones sobre el tema}

\section{La política en los nombramientos y las decisiones de los jueces}

En un grupo importante de trabajos de investigación, la relación entre magistrados y política se analiza a través de varias dimensiones que

La AMFJN se creó en 1928 y agrupa a los jueces de la Justicia Nacional de la ciudad de Buenos Aires y de la Justicia Federal en todas las instancias; también a fiscales, defensores y a los funcionarios judiciales. La AJUFE fue creada en mayo de 2017 y reúne solo a los jueces federales de todo el país. 
serían relevantes mencionar. Un subgrupo de estas publicaciones lo hace a partir de los criterios utilizados por los presidentes para nominar y por los senadores para prestar su acuerdo a los jueces federales. Nancy Scherer (2017), para los tribunales inferiores, y Christine Nemacheck (2017), para el caso de la Corte Suprema, tienen dos de los trabajos más completos sobre el análisis de la bibliografía existente para el caso de los EEUU.

Según surge del trabajo de Scherer, existen dos grandes formas de clasificar los mencionados criterios. Uno de ellos es el denominado patronage appointments en donde el cargo de magistrado no era más que una recompensa por los servicios políticos prestados (Bell, 2002; Howard, 1981). El otro es denominado ideology appointments, que está íntimamente vinculado con la transformación de las estructuras de los partidos en los EEUU y con la consolidación de distintos grupos que comenzaron a movilizar recursos materiales y económicos en favor de distintos candidatos (Aldrich, 1995; Frymer \& Yoon, 2002; Gibson, Frendreis \& Vertz, 1987). Los activistas de los mencionados grupos comenzaron a reclamar "the 'Right' kind of judges appointed" (Scherer, 2017 , p. 10) porque creían que el cambio social podría llegar con las decisiones tomadas en las cortes federales (Rosenberg, 1991; Scheingold, 1974).

Otros autores analizan las posiciones ideológicas, las adscripciones partidarias y sus vínculos con grupos de interés, no para analizar los procesos de selección sino para poner la lupa en las decisiones jurisdiccionales de los magistrados (D'Elia-Kueper \& Segal, 2017; Perkins \& Collins, 2017). Los estudios mencionados o bien afirman que la filiación demócrata o republicana es un indicador de sus creencias políticas (Pinello, 1999) o que la ideología de los jueces es algo mucho más amplio que el partido con el cual se los asocia (Gillman, 2001).

La relación entre las elites, los grupos de interés y las decisiones tomadas por los magistrados recibieron distintos tratamientos. Por ejemplo, Baum (2017) sostiene que las elites en tanto audiencias modelan los pensamientos de los jueces en torno a los casos sobre los que deciden.

Aparece también el extrajudicial lobbying, tema que está vinculado a las invitaciones que reciben los magistrados para dar charlas, confe- 
rencias o impartir clases en otros países como forma de aproximación a los magistrados por parte de determinados grupos de interés (Black, Owens \& Armaly, 2016).

\section{Los jueces y la política en los procesos de reforma judicial}

Los procesos de reforma impulsados en los poderes judiciales latinoamericanos han recibido un tratamiento privilegiado por parte de los investigadores académicos de la región y del mundo (Acuña, 2002; Acuña \& Alonso, 2003; Bill Chávez, 2007; Garoupa \& Guinsburg, 2009; Pásara, 2015) ${ }^{6}$. Aquí se integra la dimensión política al análisis de las reformas judiciales en América Latina de una manera particular. Las modificaciones hacia el interior de los poderes judiciales son consideradas institucionales y se dan en el marco de cambios políticos externos a la organización. Según los relevamientos bibliográficos realizados por Pásara (2003) y Arellano Ríos (2008), estos trabajos sostienen que los cambios institucionales mencionados son reflejo de procesos políticos que se dan en otros ámbitos.

De todas formas, existen, para el caso latinoamericano, una serie de trabajos que tienden a mirar los procesos políticos internos al poder judicial, tratando de complejizar las dinámicas de interacción con los otros poderes del Estado. Las estrategias utilizadas son muchas y van desde el análisis de las trayectorias de los magistrados, sus decisiones jurisdiccionales, hasta los vínculos de sumisión, negociación y disputa con los ejecutivos de turno, sean de facto o democráticos (Almeida, 2010; Basabe Serrano, 2011; Hilbink, 2007).

Para el caso argentino, y con líneas de análisis cercanas a las que propongo en este trabajo, existe un conjunto de trabajos que analizan, a partir de la segunda mitad del siglo XIX, la conformación de la justicia federal, las trayectorias profesionales y las redes políticas de aquellos que llegaron a ejercer la magistratura. En estos trabajos es importante

\footnotetext{
6 La especial atención que recibieron durante este período no siempre fue tal. Según Luis Pásara (2003), y retomando sus argumentos, Arellano Ríos (2008), las ciencias sociales latinoamericanas prestaron poca atención a la investigación sobre los poderes judiciales latinoamericanos debido a la postura marxista dominante durante los 70's. $\mathrm{Al}$ ser un poder del Estado, el tema es principalmente superestructural, por lo que las determinaciones son estrictamente económicas y de clase. Tal vez un ejemplo de estos trabajos sean los realizados por Bergalli (1999). Para el caso europeo, los trabajos de Griffiths $(1977,1993)$ son otros ejemplos del enfoque mencionado.
} 
rescatar cómo se describe la marca de la política en el proceso instituyente de la justicia federal argentina; marca que fue ocultándose, aunque sin perder fuerza, a medida que esta última fue consolidándose. (Bosch, 1998; Candioti, 2018; Lanteri, 2011; Levaggi, 1997; Palacio, 2018; Zimmermann, 2007).

Contemporáneamente, a través de diversas etnografías, se han analizado los vínculos y las relaciones políticas en las formas de acceso a los cargos de magistrados, en particular, y al Poder Judicial, en general, y también los vínculos que establecen los magistrados con otras instituciones y actores. Estos procesos de interacción son analizados a partir del intercambio de favores, el don y el contra don, y la noción de familia judicial. En este sentido, reconstruyen un universo de reglas informales y personales que debe ser analizado junto al ya conocido universo formal de los códigos, los procedimientos y las normativas. (Eilbaum, 2008; Sarrabayrousse, 2004, 2015; Tiscornia, 2007).

Otros trabajos analizan la relación entre jueces y política una vez que han llegado a ocupar sus cargos, avanzando sobre los factores que influyen en las decisiones de los magistrados y sobre la judicialización de la política y la politización de la justicia (Ansolabehere, 2005; Böhmer, 2013; Llanos \& Figueroa Schiber, 2007; Smulovitz 1995); También discusiones sobre la división de poderes, la independencia judicial y la distinción entre mundo jurídico y mundo político (Bielsa \& Graña, 1996; Gargarella, 1996; Sagüés, 1978, 2005).

Por último, hay investigaciones que avanzan en el análisis de la relación entre jueces y política desde diversas aproximaciones. Algunas se centran en el análisis de la independencia externa e independencia interna del Poder Judicial; otras se orientan hacia la comprensión del comportamiento de los tribunales y las actitudes de sus integrantes; también al análisis de trayectorias, al corporativismo y la dependencia de los tribunales inferiores de los superiores (Donatello \& Lorenc Valcarce, 2018; Donatello \& Nachón, 2019; Guemureman, 2010; Roth, 2007).

De lo dicho en general sobre los textos, quiero agregar algunas apreciaciones particulares asociadas al análisis del caso argentino. En primer lugar, todos, a su manera, ponen sobre relieve la marca de la negociación y la disputa política hacia el interior del PJN. Algunos de ellos señalando el vínculo político entre la CSJN y las instancias inferiores del Poder Judicial, remarcando el rol de la AMFJN en este proce- 
so (Ansolabehere, 2005). También, la existencia de un statu quo judicial, que tiene poder de presión sobre la Corte, en donde el apego a los códigos en detrimento de la constitución nacional expresa la voluntad de conservación del estado de las cosas tal cual son (Böhmer, 2013)7

Otro punto a destacar es el análisis del funcionamiento interno del PJN en su conjunto y no solo de su dimensión jurisdiccional. Se suma a las reglas formales vinculadas a los códigos y reglamentos el análisis de reglas informales asociadas a las relaciones personales y el clientelismo, las cuales influyen sobre los nombramientos de empleados y funcionarios (Sarrabayrouse, 2004) ${ }^{8}$, y en las negociaciones corporativas entre abogados y jueces en el ámbito del Consejo (Böhmer, 2013).

Por último, el análisis del funcionamiento del Consejo de la Magistratura y el de la Comisión de Selección y de Escuela Judicial, sobre todo respecto al tema de las subrogancias y las formas de presión interna desarrolladas por los magistrados para nombrar personas afines a sus intereses es muy importante en el artículo de Roth (2007). En este último, se puntualiza el protagonismo de la AMFJN, y el de las listas que la componen, las cuales buscan que sean los actuarios quienes tengan las mayores chances de acceder a las mismas ${ }^{9}$.

\section{La propuesta metodológica y el recorte del objeto}

\section{El recorte del objeto y las dimensiones de análisis}

Durkheim (1997) dijo que la explicación de los hechos sociales había que ir a buscarla en la constitución del medio social interno. Este último es el espacio en donde se relacionan las personas y las cosas.

\footnotetext{
$7 \quad$ Smulovitz (1995) sostiene que, a partir de 1930, la subordinación de la CSJN al poder político adquiere fundamentación jurídica, polemizando con Oyhanarte (1969), quien decía que esta última solo aceptaba la legalidad de facto bajo la condición que se respeten las garantías individuales aseguradas por la Constitución. La posición de Oyhanarte es asociada por Zaffaroni (1994) a la modificación del perfil sociológico del juez. Según este autor, los jueces comienzan a presentarse como técnicos asépticos, cuando en realidad lo que buscan es protegerse detrás de esa fachada para capear el clima de inestabilidad política por el que transitaba el país.

8 Otros trabajos proponen planteos similares, como los de Tiscornia (2007) y Martínez (2007).

$9 \quad$ Luego de la creación del Consejo de la Magistratura, y con anterioridad al fallo Uriarte de la CSJN, y a las Acordadas, que regularon el régimen de subrogancias por vía pretoriana, existieron cuatro sistemas distintos que aceptaban que los secretarios subrogaran como magistrados en los juzgados que se encontraban vacantes (Posdeley, 2018).
} 
Las primeras son el factor dinámico, su fuerza motriz, y entre las segundas, contaba a "los productos de la actividad social anterior, el derecho constituido, las costumbres establecidas, etc." (p. 123).

Esta concepción es mi punto de partida en términos metodológicos. Como voy a desarrollar en breve, los magistrados, sus relaciones entre sí y con los otros actores dentro del poder judicial se encuentran mediadas por dictámenes, resoluciones y fallos que muchas veces, además, se terminan convirtiendo también en cristalizaciones de las disputas hacia el interior del PJN.

Mi objetivo será, entonces, analizar el factor dinámico del proceso que tiene como resultado la cristalización señalada. Para eso, voy a retomar una tipificación mencionada en la introducción del trabajo, la que me servirá tanto para delinear el medio social aludido como para desarrollar el planteo metodológico ${ }^{10}$. Presento, entonces, bajo el formato espacio de propiedades, la tipología mencionada siguiendo los desarrollos de Becker (2009).

Tabla 1

Espacio de propiedades

\begin{tabular}{llll}
\hline & & \multicolumn{2}{c}{$\begin{array}{c}\text { Respuesta de los magistrados } \\
\text { frente a pedidos por causas }\end{array}$} \\
\hline \multirow{3}{*}{$\begin{array}{l}\text { Mecanismos de } \\
\text { persuasión }\end{array}$} & Presión & Tipo 1) & Tipo 2) \\
\cline { 2 - 4 } & Convicción & Tipo 3) & Tipo 4) \\
\cline { 2 - 4 } & Ambos & Tipo 5) & Tipo 6) \\
\cline { 2 - 4 } & Ninguno & & \\
\hline
\end{tabular}

Fuente: Elaboración propia.

Clasifico aquí la independencia de los jueces frente a la intervención de agentes externos al poder judicial que tratan de influir sobre sus decisiones. En las columnas, los magistrados se dividen entre aquellos que ceden frente a estas situaciones y aquellos que no. En las filas aparecen los mecanismos utilizados para convencer a los jueces: distintos mecanismos de presión, la apelación a la convicción, por tratarse de jueces afines en términos ideológicos, y la utilización de ambas estrategias.

10 Desde mi punto de vista el planteo a desarrollar no puede escindirse de los problemas conceptuales presentados en el apartado anterior. 
Agregamos también la categoría Ninguno que, si bien en principio parecería no tener coherencia lógica, además de cumplir con el principio de exhaustividad, tiene un sentido que voy a presentar a continuación.

Los jueces tipificados como 2), 4) y 6) son los que clásicamente pueden ser clasificados como jueces independientes: ni por presión y/o convicción ceden frente a los pedidos por causas sensibles. Por el contrario, los clasificados como 1), 3) y 5) ven afectados su independencia por ceder frente a estas situaciones. Con relación a estos últimos, el 3) refiere al magistrado que es considerado, por aquellos que hacen el pedido, como "uno de los nuestros"; y el 1) son aquellos que son sometidos a las distintas variantes de lo que comúnmente se conoce como "carpetazo"11. El tipo 5) son aquellos que pueden clasificarse dentro de la afirmación de un magistrado entrevistado "por si dudan, para los nuestros también hay carpetas" ${ }^{\prime 2}$.

Lo que busco expresar con las celdas grisadas es que si no hay mecanismos de persuasión, no podemos saber a ciencia cierta cómo reaccionaría ese magistrado frente a pedidos por causas sensibles. Como no lo expreso de forma explícita, supongo que esos pedidos pueden provenir tanto de un sector interno del poder judicial como de un sector externo. Esto no es otra cosa que hacer referencia a lo que comúnmente se llama independencia externa e independencia interna.

De todas formas, y como ya mencioné, es muy difícil hablar de afecciones puras a la independencia interna, así como también poder discernir rápidamente que la presión es externa por identificar, como una suerte de cadena de mando, dónde el operador externo es el jefe del camarista que, a su vez, es el jefe del juez de primera instancia.

Además, el caso de la independencia interna también presenta una particularidad que es importante discutir y que está relacionada con lo que dije anteriormente. Por ejemplo, en el caso de pedidos provenientes del ejecutivo, es posible establecer la diferenciación por convicción a partir la reconstrucción de las redes y trayectorias políticas previas del magistrado. En el caso de los jueces, ¿cómo se cuentan los

11 Por esta categoría generalmente se hace referencia a información comprometedora sobre los magistrados que es utilizada en ciertos momentos para presionarlos.

12 En adelante, las entrevistas se citarán de la siguiente forma: (Entrevista a Juez Federal, CABA). 
propios?, ¿en base a qué características se construyen las redes de confianza entre los magistrados federales y nacionales?

Los temas desarrollados plantean la necesidad de estudiar a los magistrados como integrantes de distintos grupos de interés que interactúan, negocian y disputan espacios de poder tanto entre ellos como con sectores ajenos al PJN.

Este recorte delinea las limitaciones que posee el espacio de propiedades presentado al inicio del apartado. En este contexto, los jueces aparecen como individuos aislados que ceden o no frente a los pedidos en función de los mecanismos mencionados, pero que no negocian ni intercambian algo a cambio o, si lo hacen, siempre está implícito que ceden. En este escenario, los de afuera siempre mandan y los adentro obedecen o bien se defienden, pero siempre de manera aislada. En efecto, en un criterio de clasificación como el mencionado, los magistrados no tienen otros intereses que los propios y no tienen grupos de referencia política que no sean los partidarios típicos.

Ambas posturas, sobre todo la defensiva, pierden de vista que, como se dice comúnmente, "en el ajedrez las negras también juegan". Esta postura parte del supuesto de que la libertad de los magistrados se define en términos negativos: solo son libres cuando existe ausencia de un impedimento externo que reduzca sus grados de libertad y que, por supuesto, esos intereses siempre ajenos a ella son generalmente políticos y económicos. Desde una mirada sociológica, queda descartada cualquier definición esencialista que suponga que si no hay presión, el juez falla en función de una forma jurisdiccionalmente legítima y no de otros intereses diferentes al anterior.

Más allá de la condena que existe en términos republicanos y de la división de poderes, no podemos dejar de aceptar como posibilidad que la presión del ejecutivo existe porque "las negras ya jugaron", es decir, porque si no intervienen la decisión ilegítima ya fue puesta en marcha. Esto no significa justificar, sino comprender que el contexto que se describe aquí no es diferente de cualquier otro proceso institucional de negociación, imposición y disputa.

En todos los casos, siempre hay imposición y nunca negociación. En referencia a lo dicho, la tabla de verdad presentada a continuación busca avanzar sobre el mencionado problema. 
Tabla 2

Tabla de verdad

\begin{tabular}{lllll}
\hline & $\begin{array}{c}\text { Ceden frente } \\
\text { a pedidos }\end{array}$ & Presión & Convicción & Negociación \\
\hline 1 & No & Sí & Sí & Sí \\
\hline 2 & No & No & Sí & Sí \\
\hline 3 & No & No & No & Sí \\
\hline 4 & No & Sí & No & Sí \\
\hline 5 & Sí & Sí & Sí & Sí \\
\hline 6 & Sí & Sí & Sí & No \\
\hline 7 & Sí & Sí & No & No \\
\hline 9 & Sí & No & Sí & No \\
\hline 10 & Sí & No & No & Sí \\
\hline 11 & Sí & Sí & Sí & Sí \\
\hline 12 & No & No & No & No \\
\hline
\end{tabular}

Fuente: Elaboración propia.

En 1), 2), 3) y 4) se contemplan los casos en donde la existencia de propuestas de negociación permite, al menos, poner en duda los motivos por los cuales no ceden a los pedidos aludidos. Los casos que van del 5) al 10) son los que típicamente responden a los intereses de este trabajo y son los que aquí van a ser puestos bajo análisis. Los casos 11) y 12) quedan descartados: el primero por obvias razones y el segundo por tratarse de una modalidad que si bien puede existir, generalmente no está asociada a cuestiones sensibles ${ }^{13}$.

Tanto el espacio de propiedad como también la tabla de verdad contemplan formalmente no solo los procesos que se desenvuelven en el ámbito jurisdiccional, sino también otros espacios en donde los magistrados y sus grupos de pertenencia intervienen. En efecto, en el caso argentino, el juez no es solamente jefe de lo jurisdiccional, sino que decide los ingresos, nombramientos (regulares e interinos) y/o ascensos dentro de los juzgados. En esta dimensión del trabajo de los magis-

13 Es lo que un entrevistado definió como el "sin compromiso, fíjate qué podés hacer" (Entrevista a Juez Federal, CABA), generalmente asociado a apurar algún trámite de un familiar o amigo, atender a un abogado, etc. 
trados, no es inusual que reciban llamados o participen en reuniones en donde se les sugieren y recomiendan personas para cualquiera de las situaciones mencionadas. Incluso, en aquellos fueros donde hay exámenes vinculados a los ascensos del personal, los llamados para revisión de notas o contemplaciones tienen cierta regularidad.

La otra dimensión es la que se abrió a partir de la reforma constitucional de 1994 con la creación del Consejo de la Magistratura de la Nación. En esta institución, que pertenece al PJN, los jueces tienen una representación de tres consejeros que son elegidos en elecciones periódicas por la AMFJN. El mismo está organizado en cuatro grandes comisiones (selección, presupuesto, disciplina y acusación, y reglamento) y está integrado, además, por un miembro del ejecutivo nacional, representantes por la mayoría y la minoría de las dos cámaras, y representantes de los abogados de la matrícula y del sector académico.

En este caso, las decisiones que deben tomarse en las distintas comisiones hacen que, en la interacción entre los consejeros jueces y el resto de los estamentos con representación hacia el interior del Consejo, se produzcan procesos de negociación, presión y disputa en torno a los distintos temas que se discuten hacia el interior de las comisiones. Sin perder de vista, además, que los magistrados no constituyen un bloque homogéneo ya que provienen de las distintas listas que forman parte de la mencionada AMFJN.

En función de lo dicho, cuando hablaba de describir cuáles son los temas por los que entran en disputa los grupos de interés que los magistrados integran, tanto entre ellos como con grupos externos al Poder Judicial de la Nación, y de analizar cómo es la dinámica de las luchas mencionadas, los intereses que defienden y cómo se construyen las posibles lógicas de alianzas para lograr cumplir sus intereses colectivos, no me estaba refiriendo solamente a los estrictamente jurisdiccional.

Entonces, el objeto de investigación, en general, quedaría definido por la representación gráfica presentada a continuación. La misma supone que la superposición constante entre lo que se llama independencia externa e independencia interna implica un proceso constante de persuasión más negociación en los distintos escenarios (Consejo de la Magistratura, Administración del juzgado y el ámbito estrictamente 
jurisdiccional) e indica cómo se expresan materialmente los mismos, indicando un primer tipo de fuentes con las que es necesario trabajar.

Esquema I. Mecanismos de persuasión y negociación

\begin{tabular}{|l|l|l|l|}
\hline $\begin{array}{l}\text { Mecanismos de } \\
\text { persuasión }\end{array}$ & Negociación & $\rightarrow$ & $\begin{array}{l}\text { Espacios o situaciones } \\
\text { en donde se expresa }\end{array}$ \\
\hline Consejo de Magistratura & & $\begin{array}{l}\text { Decisiones en la } \\
\text { comisiones }\end{array}$ \\
\hline Administración del juzgado & $\longrightarrow$ & $\begin{array}{l}\text { Nombramientos y } \\
\text { ascensos }\end{array}$ \\
\hline Jurisdiccional & $\longrightarrow$ & $\begin{array}{l}\text { Resoluciones, interlo- } \\
\text { cutorias y sentencias }\end{array}$ \\
\hline
\end{tabular}

Fuente: Elaboración propia.

Por una cuestión de espacio, me voy a enfocar en este trabajo en las decisiones de la Comisión de Selección y de la Escuela Judicial del Consejo de la Magistratura de la Nación y aquellos aspectos extrajurisdiccionales que refieren a los ascensos de empleados y funcionarios hacia el interior de los juzgados y vocalías. El problema jurisdiccional implica un abordaje especial que extendería más allá de lo aceptado. De todas formas, en las conclusiones de este artículo voy a esbozar posibles líneas de análisis que pueden integrar, de manera conjunta, la reflexión sobre las tres dimensiones.

Más allá del espacio disponible en este trabajo, existe otro motivo que lleva a plantear este recorte: analizar los procesos de negociación y disputa en los nombramientos hacia el interior de los juzgados y salas puede aportar ciertas pautas sobre si es la propia dinámica del Consejo la que lleva a los magistrados a entrar en los procesos de negociación y disputa por tener que vincularse con los otros estamentos que lo conforman o en definitiva son prácticas que en otros contextos ya venían realizando.

\section{Las fuentes y las técnicas de recolección de la información}

Para este trabajo en particular analicé 40 entrevistas en profundidad a magistrados nacionales y federales de primera y segunda instancia de todo el país, de los cuales 5 ocuparon cargos como Consejeros de la Magistratura por el estamento de los jueces. Una operación similar llevé adelante con 15 entrevistas realizadas a funcionarios del mencionado Consejo y se presenciaron alrededor de 25 entrevistas a postulantes 
para cubrir cargos de magistrados de primera y segunda instancia en todo el territorio federal.

Los criterios de confidencialidad adoptados fueron maximizados en el caso de los entrevistados que fueron Consejeros, porque es muy difícil referirse a ellos en el contexto de un período sin identificarlos más allá de no dar su nombre. Lo mismo sucede si hago referencia al color de la lista a la que pertenecen en la AMFJN. En este sentido, opté por hacer una lectura que capte las regularidades existentes sin hacer distinciones que puedan revelar la identidad de los entrevistados.

Las entrevistas están estructuradas en cinco grandes bloques que pueden convertirse en seis si el entrevistado fue elegido como Consejero o tuvo un cargo electivo en la AMFJN. En primer lugar, hay un bloque dedicado a su familia, ocupación y profesión de sus familiares directos. En todos los casos se releva la información acerca de su socialización religiosa y educativa. En segundo lugar, hay preguntas asociadas a su experiencia laboral, universitaria y de participación política, en el caso de que la hayan tenido. En tercer lugar, su experiencia en el PJN, en el caso de haber sido empleados y/o funcionarios antes de llegar a su cargo actual. Hay consultas específicas para aquellos entrevistados nombrados luego de la creación del Consejo de la Magistratura; indago sobre los concursos a los que se presentó, sus recuerdos sobre las entrevistas ante la Comisión de Selección y, por último, sobre la entrevista frente a la Comisión de Acuerdos del Senado de la Nación. En el caso de los jueces elegidos antes de la reforma constitucional de 1994, las preguntas están orientadas a la descripción del proceso que los llevó al cargo. En ambos casos hay interrogantes vinculadas a su participación en la AMFJN y otras organizaciones en las hayan participado. El cuarto bloque es sobre su experiencia en la docencia universitaria o de otro tipo, sus actividades de investigación, publicaciones si es que las tiene. En quinto lugar, se indaga, al igual que se hizo con sobre sus padres y hermanas/os, sobre su esposa/o e hijas/os, en caso de que esté casado y los tenga.

El último bloque, dedicado a aquellas personas que fueron Consejeros y/o tuvieron un cargo en la AMFJN, las preguntas giran en torno a cómo fueron elegidos para postularse al cargo y cómo fue la campaña; también sobre la dinámica del trabajo cotidiano, los vínculos con las listas opositoras dentro de la AMFJN y con el resto de los estamentos; 
por último, sobre las comisiones en las que participaron, sus evaluaciones y el funcionamiento de las subcomisiones de selección a la hora de definir los resultados de las entrevistas realizadas.

El recorte del objeto y las técnicas propuestas generan el marco para corroborar la hipótesis exploratoria planteada en la introducción. Necesito, además, aportar la evidencia empírica necesaria para ello, cuestión a la que me voy a abocar en el próximo apartado.

\section{El Consejo, los concursos, los nombramientos y la política}

Voy a presentar aspectos vinculados a las entrevistas y observaciones realizadas, haciendo hincapié en los mecanismos de persuasión y negociación que se abren en la Comisión de Selección y Escuela Judicial del Consejo de la Magistratura y en la administración del juzgado referida a los ingresos, nombramientos y ascensos ${ }^{14}$. El objetivo es señalar que las prácticas de los jueces hacia el interior de la oficina judicial que conducen no es muy diferente de las formas en que se manejan en el Consejo. Este tema será relevante a la hora de encarar las conclusiones de este trabajo en el último apartado.

\section{Las representaciones de los jueces frente a la politica}

La primera reacción que tienen los magistrados entrevistados es excluir la política del poder judicial. El punto en el que generalmente coinciden es que la política es inoculada desde el exterior y se expresa en lo que algunos de ellos llaman "jueces adictos" o "infiltrados". Ambos tipos no necesitan ser presionados para fallar de acuerdo con los intereses de los gobiernos de turno. De esta forma, y según las posiciones de los entrevistados, aparecían conceptos como "los jueces de la servilleta", "la mayoría automática", "justicia legítima”, "los cortesanos en comisión", "la mayoría peronista"15, entre otras formas de vincular a magistrados con intereses externos al PJN.

En las entrevistas identifico, también, a un grupo que si bien admite presiones e intereses externos, sostienen que ellos nunca las sufrie-

Ver el esquema 1 del apartado metodológico.

Las expresiones citadas corresponden a diferentes entrevistados. 
ron. Por ejemplo, comparando el período en el que fueron nombrados con el actual, sostienen: "Mirá que a mí me nombró el gobierno X pero nunca me llamaron para pedirme nada. Ahora, por lo que se ve en los medios pareciera distinto"16; otros que reconocen la presión, porque alguien les contó: "Según me dijeron, te lo hacen saber, generalmente por alguien de adentro, por un par tuyo" ${ }^{17}$. Existen también aquellos que aceptan la presión pero le ponen límites: "Frente a un pedido, uno puede hacer el esfuerzo en la interpretación, pero sino da, no da"18.

Aquellos que admiten haber recibido presiones sostienen que la forma más común son las denuncias por mal desempeño al Consejo de la Magistratura. Este tema aparece con cierta regularidad en las entrevistas y como una de las cuestiones centrales en un grupo importante de magistrados. De hecho, según algunos entrevistados, estas acusaciones trajeron disputas al interior de la AMFJN y fueron una de las causas de la creación de la Asociación de Jueces Federales (AJUFE).

Por ejemplo, algunos entrevistados miembros de AJUFE sostienen que en la actual conducción de la AMFJN "hacen cola para defender a los jueces nacionales denunciados, pero no aparece ninguno cuando denuncian a un juez federal". ${ }^{19} \mathrm{En}$ este sentido, las líneas opositoras dentro de la primera asociación mencionada aprovechan la situación y sostienen que se crean nuevas instituciones porque existe un problema de representación. Dicen: "El oficialismo de la AMFJN no representa los intereses de los magistrados nacionales y federales" ${ }^{20}$. Otros, con una posición todavía más dura, pero con el grabador apagado, sostienen: "Vamos a ver con quién negocian (en alusión al ejecutivo) si se consolida el traspaso (...), si con los que representan a los jueces nacionales o los que representan a los jueces federales" ${ }^{21}$.

(Entrevista a Juez Federal, CABA).

(Entrevista a Juez Federal, CABA).

(Entrevista a Camarista Federal, CABA).

(Entrevista a Camarista Federal, CABA).

(Entrevista a Camarista Federal, CABA).

(Entrevista a Camarista Federal, CABA). Esta disputa se encuentra en pleno desarrollo y muchos la vinculan al cuestionado traspaso de la llamada justicia nacional al ámbito de la Ciudad Autónoma de Buenos Aires. En este sentido, si el traspaso efectivamente se diera, AJUFE estaría en condiciones de solicitar formalmente los lugares que le corresponden a la AMFJN en el Consejo de la Magistratura de la Nación. 


\section{Concursos, politica y negociación}

Existe otro grupo para el cual la relación entre jueces y política adquiere otro tono, sobre todo cuando se refieren a los concursos por los cuales transitaron y al tipo de acciones que realizaron una vez que quedaron en el listado de aquellos postulantes que fueron citados a las entrevistas en la comisión de selección. Estas prácticas involucran un mediador, que en algunos casos puede ser más de uno y de distintas procedencias para un mismo postulante. Estos últimos impulsan su postulación en el transcurso que va desde los días previos a la entrevista con los consejeros al momento en que se firma el dictamen con la terna que se eleva al plenario.

Algunos entrevistados, que admiten ocupar este lugar, pueden afirmar: "Yo soy un lobista de jueces"22 o "que me disculpen los abogados de la matrícula pero yo defiendo los intereses de los judiciales" ${ }^{23}$. Más allá de que la figura de este mediador existía tanto con anterioridad como con posterioridad a la creación del Consejo de la Magistratura, existen diferencias entre las apreciaciones de los magistrados que podríamos denominar aquí como preconsejo y los postconsejo. Para graficar esta idea me gustaría recurrir a un registro de campo redactado al salir de una entrevista que ayudaría a profundizar esta temática.

Conocí al magistrado entrevistado con anterioridad al desarrollo de esta investigación (...) Me decía que llegar a la cámara era para él "como la frutilla del postre" (...) pasaron más de tres años del último encuentro, pero como tenía su contacto $-\mathrm{y}$ cierta confianza- me animé a escribirle un mensaje de texto, el cual contestó, aceptando recibirme (...) La entrevista transitó por lugares comunes respecto a otras que ya había realizado. Me comentó que llegó a juez de primera instancia porque una conocida suya estaba casada con un senador, quien le acercó su nombre al entonces Ministro de Justicia. Hasta ahí nada que no hubiera escuchado con distintas variantes. Lo que me llamó la atención fue que, más adelante en la entrevista -habrán pasado quince minutos luego del comentario recién mencionado-, cuando le pregunté, recordando que me había manifestado su intención de llegar a ser camarista, si se había presen- 
tado a algún concurso en el último tiempo me contestó: "Ahhh no... Eso está todo arreglado" (... $)^{24}$.

El registro de campo mencionado aparece con regularidad en los magistrados preconsejo. La lógica del argumento era siempre similar. El juez designado con anterioridad al Consejo manifestaba que los concursos no garantizaban nada. Por ejemplo: "Antes los lugares estaban bien definidos... un peronista, un radical y un académico. Hoy no sabés quiénes los recomiendan" ${ }^{25}$. También, "las personas que te recomendaban se jugaban su prestigio. No se recomendaban personas así porque sí... Eso hoy no sucede" 26 . "Yo tengo un amigo que siempre dice cuando entran a su despacho... quédese tranquilo, aquí nadie fue elegido por concurso"27.

\section{Las listas de la AMFJN en los procesos de selección}

Para los magistrados, o aspirantes, esos mediadores pueden estar asociados a las listas de la AMFJN y muchas veces se describen como espacios de contención para los postulantes a los concursos. "Es la garantía de que alguien te va a defender en el Consejo"28; "Si no pertenecés, nadie pelea por vos" 29 . O como también dijo un entrevistado: "Para que te puedan bautizar, primero tenés que conseguir un padrino" ${ }^{30}$. De todas formas, estas relaciones se complejizan si se observan las relaciones que puede haber entre las distintas listas de la asociación y los ejecutivos de turno. En este contexto, padrinos pertenecientes a listas menos cercanas a los ejecutivos pueden recomendar a sus protegidos y no ser los encargados de pedir por ellos ya que eso "te va a hundir más que ayudarte" ${ }^{31}$.

Cómo estos gestores hacen su trabajo o con quiénes hablan para lograr su objetivo no es algo que a los entrevistados les interese. Incluso, algunos llegan a sostener que no saber esas cosas (cómo lo hacen y con quién) les da libertad. De todas formas, pueden reconocer el éxito de la

\footnotetext{
(Entrevista a Juez Nacional, CABA).

(Entrevista a Juez Federal, Provincia).

(Entrevista a Camarista Federal, Provincia).

(Entrevista a Juez Federal, Provincia).

(Entrevista a Juez Federal, Provincia).

(Entrevista a Juez Federal, CABA).

El registro surge de una charla informal con un asesor del Consejo de la Magistratura.

(Entrevista a Camarista Federal, CABA)
} 
intervención cuando un asesor de uno de los consejeros miembro de la subcomisión que lleva adelante su concurso lo llama para una entrevista personal e informal. En estas reuniones existe cierto ritualismo donde se habla de la trayectoria del postulante y en donde se le informa gracias a quién consiguió la entrevista y, eventualmente, pueden agregar: "muchas personas pidieron por usted"32.

Las mencionadas subcomisiones están integradas por dos consejeros que son los que llevan adelante la tramitación del concurso. Desde las entrevistas surge que es muy común que suene el teléfono para pedir por candidatos y que esas llamadas son de distintos tenores. Van desde el "fíjate qué podés hacer", hasta el "que quede bien posicionado, sino no te doy mi voto para $\mathrm{X}$ tema" ${ }^{33}$.

La existencia o no de gestores que piden por un candidato también es un emergente que no pasa desapercibido en las observaciones y en las charlas informales. Generalmente se sostiene, por parte de empleados del Consejo, en relación a postulantes con pocas chances de ser elegidos: "y qué querés... Si no llamó nadie para pedir por él /ella" ${ }^{34}$. En estos casos aparecen algunos candidatos que comienzan a autogestionar la "venta" de su imagen como candidatos elegibles frente a actores con poder decisión y, por supuesto, con disímiles niveles de efectividad.

De algunas charlas informales surgen ejemplos al respecto: “Pobrecita/o se encuentra con 'el ordenanza del consejero' y le cuenta de su concurso" 35 . También refieren que los candidatos que autogestionan la mediación utilizan los lugares más extraños para acercarse a personas con poder de decisión. Por ejemplo, "en un casamiento de personas que pertenecían al poder judicial, un juez/a de primera instancia que estaba ternado/a para camarista se confundió y pensó que una de las personas que estaba sentado en su mesa era un importante

(Entrevista a Juez Federal, CABA).

Comentario off the record.

El registro surge de una charla informal con un asesor del Consejo de la Magistratura. El registro surge de una charla informal con un asesor del Consejo de la Magistratura. 
dirigente de una agrupación política y le estuvo hablando toda la noche de su concurso" ${ }^{\prime 36}$.

En algunos casos, comienzan a "peinar su agenda" y a llamar a todos sus contactos forzando, en algunos casos, entrevistas con representantes del ejecutivo. De esta forma, muchos entrevistados, en referencia a ese momento en sus carreras, dicen: "En ese momento pensé yo llamo, total no pierdo nada"37, o "me dije, perdido por perdido llamo"38.

El caso de los autogestionados tiene una característica en común, más allá del resultado de sus acciones e intervenciones. Generalmente, hacen referencia al desgaste y la alta exposición que debieron aceptar frente a sus pares, pero implícitamente admiten que si alguien no se ocupa (sean ellos u otros) "el trámite no sale".

En esta línea, un magistrado expresó esta situación de manera contundente mediante un comentario off the record: "El poder no elige enemigos, con concursos o sin concursos" ${ }^{\prime 39}$. En su relato, el rol en la elección de amigos tenía como protagonistas tanto a miembros del PEN como a miembros del PJN y no precisamente mostrando acuerdo entre ambas partes. En este sentido, en los comentarios del entrevistado se entrelee que no era solo el primero el que no elegía enemigos, sino que el segundo tampoco. En sus dichos no había una versión simplificada de los procesos de interacción (y disputa) en donde el PJN y el PEN compartían los mismos amigos y enemigos como para no generar conflictos a la hora de la selección de jueces.

En resumen, lo que surge de las entrevistas es que el proceso de tramitación de los concursos se abre en el marco de la comisión de selección y de las subcomisiones que llevan adelante cada concurso en particular, procesos de negociación y de presión acerca de cómo estarán conformadas las ternas. De estos procesos, participan los magistrados, en tanto consejeros y en tanto postulantes.

En tanto consejeros pidiendo, presionando y negociando con distintas intensidades por los candidatos que apoyan y en tanto postulan-

\footnotetext{
36 El registro surge de una charla informal con un asesor del Consejo de la Magistratura.

37 (Entrevista a Juez Federal, CABA).

38 (Entrevista a Juez Federal, Provincia).

39 (Entrevista a Juez Federal, CABA).
} 
tes buscando interlocutores que puedan negociar por ellos sus lugares dentro de los concursos a los que se presentan. Los resultados pueden ser diversos, aunque efectivos en algunos casos, porque son prácticas que aparecen con cierta regularidad en los dichos de los entrevistados.

\section{Nombramientos, ascensos y exámenes. Lo que se aprende en el juzgado se aplica en el Consejo}

En este apartado voy a trabajar el rol de jueces y camaristas en sus juzgados y vocalías en lo que referido a los nombramientos, ascensos de los empleados y funcionarios y, en algunos casos también, de magistrados. Como ya dije en la introducción del trabajo, el juez, además de ejercer la autoridad jurisdiccional dentro del juzgado, ejerce también la jefatura administrativa de la oficina judicial a su cargo. Las cámaras federales y nacionales, cualesquiera sean, ejercen el rol de superintendencia respecto a los temas mencionados lo que puede generar conflictos entre los juzgados de primera instancia y las alzadas, porque son estas últimas las que deben ratificar las decisiones que se toman en estos temas ${ }^{40}$.

De todas formas, y no está de más aclararlo, las decisiones tomadas en estos temas por las cámaras no siempre se corresponden con lo solicitado por los juzgados de primera instancia. En este sentido, existe toda una cadena de negociaciones y, como diría María José Sarrabayrouse, de intercambio de favores y disputas que estructuran las relaciones entre jueces y camaristas que muchas veces también están vinculadas a las listas a las que pertenecen en la $\mathrm{AMFJN}^{41}$.

El objetivo es mostrar que lo que los funcionarios y los magistrados hacen en los juzgados en los que están a cargo es muy parecido a lo que condenan sobre la tramitación de los concursos en el Consejo. Tanto entrevistados como informantes clave me describieron sus propias experiencias de trabajo y las situaciones por las que debieron experimentar en sus trayectorias profesionales.

40 Si bien la CSJN es formalmente la autoridad máxima, es muy raro que vaya en contra de una decisión de las cámaras correspondientes en lo referido a los ingresos, nombramientos y ascensos.

${ }_{41}$ Por ejemplo, la lógica de los nombramientos cruzados analizados por la autora (Sarrabayrouse, 2004). 
Varios entrevistados me hablaron del “vacío". Esta situación se da cuando el magistrado quiere que el cargo que es ocupado por X pase a ser ocupado por Y. En este sentido, se deja de darle trabajo, no se le dirige la palabra - o lo hace a través de la persona por quien lo quiere reemplazar-, no le firma o le corrige los escritos buscando errores sin sentido. Lo que se busca es desgastar anímicamente a la persona para que renuncie y poder designar en su lugar a la persona deseada.

Este tipo de discrecionalidades también se da en los ascensos. Muchas veces no se respeta el escalafón, se asciende y se nombra personas cercanas a las magistradas/os y/o a los camaristas. Este tipo de situaciones genera conflictos en el interior de los juzgados lo que lleva muchas veces a la intervención del gremio. Los conflictos no siempre se resuelven según los intereses de los jefes de la oficina judicial, pero las existencias de estas situaciones muestran la regularidad en que este tipo de situaciones se repite en el interior del PJN.

En los fueros, en los que hay examen para los ascensos ${ }^{42}$, generalmente se sostiene que situaciones como las descritas en el párrafo anterior no suceden, pero esto no es del todo así, sobre todo en aquellos casos vinculados a los cargos de funcionarios. Por ejemplo, se describen conflictos entre algunos de los evaluadores y algún empleado con quien no tenga buena relación. En estos casos, puede haber discusiones entre los miembros del tribunal porque a veces la animadversión con aquellos que están rindiendo es tan evidente que hace que el resto de los jueces intervenga tratando de poner paños fríos a la situación. Hay magistrados, que al ver la lista de los inscritos, avisan que hay una persona a la cual no quieren aprobar, lo que también puede desatar discusiones.

Estos casos no son los únicos. Algunos señalan que los magistrados que forman parte de los tribunales de evaluación muchas veces deben excusarse porque hay empleados de sus juzgados rindiendo. Frente a estas situaciones, hay ciertos acuerdos tácitos en función de los cuales a los empleados de los jueces que evalúan "no se les tira con munición gruesa" o, como dijo un entrevistado, "es un quid pro quo".

\footnotetext{
$42 \quad$ Al ser las diferentes cámaras las que ejercen la superintendencia sobre sus subordinados, son también las que deciden las formas en que se dirimen los ingresos, ascensos y nombramientos de sus empleados.
} 
También, y de la misma forma en que se manejan los pedidos de nombramientos, existen llamados solicitando revisiones de las notas, pidiendo cambiar las fechas de los exámenes porque el hijo/hija del/ la magistrado/a tenía un viaje programado al exterior. Es importante aclarar que estos pedidos no necesariamente prosperan, pero sí existen. En este sentido, son moneda relativamente corriente, lo que abre procesos de negociación y de devolución de favores entre los jueces en cualquiera de sus instancias.

Si el poder no elige enemigos para ejercer el cargo de magistrado, tampoco lo hace para el cargo de secretario. En este contexto, y como dijeron algunos entrevistados el color de la lista en la que uno adscribe en la AMFJN, es generalmente transmitido de "arriba hacia abajo" o, como dijo un entrevistado. "vos sos del color de tu juez"43.

Había dicho al principio del apartado que estas situaciones podían incluso trasladarse al nombramiento de magistrados. Este tipo de situaciones se dan en el contexto de las llamadas subrogancias. Estos temas aparecen con mucha regularidad en las entrevistas, pero sistemáticamente son los momentos en los que con mayor asiduidad me solicitan que apague el grabador.

En una entrevista, un juez de cámara me dijo: "Entonces, el Dr. $\mathrm{X}$ sacó un papelito del bolsillo en el que tenía anotados una serie de nombres y nos dijo al resto: 'quiero que estas personas subroguen los juzgados vacantes'. A lo que yo le dije: 'no estás respetando el procedimiento para realizar estos nombramientos. Si es por nombres, yo también tengo los míos"' ${ }^{\prime 4}$.

También, surgió de una serie de charlas con informantes claves, discusiones y conflictos vinculados a cómo cubrir cargos en cámaras con un número importante de vacantes. Por ejemplo, en un caso se decidió hacer la selección al azar de entre los jueces de primera instancia del fuero para cubrir esos cargos. Luego del resultado, los comentarios hablan de poca transparencia del sorteo. Según un entrevistado, "casualmente la/el que salió sorteada/o es de la misma lista que el/la camarista con mayor poder dentro de la cámara. Y, casualmente, tam-

(Entrevista a Camarista Federal, Provincia).

Comentario off the record. 
bién el nombre del segundo se sabía antes de que se hiciera el sorteo" ${ }^{45}$. Además, las descripciones que hacen los entrevistados de los procesos terminan cuestionando también los criterios que se están utilizando para cubrir los lugares que dejarían los magistrados que se hacen cargo de las vocalías en el tribunal de alzada. "Los candidatos no están habilitados para cubrir esos cargos, pero casualmente representan en partes iguales a dos listas de la AMFJN"46. En este caso, no debe perderse de vista que, además, los secretarios que son elegidos para subrogar juzgados vacantes, votan como jueces en las elecciones para elegir representantes ante el Consejo por el estamento de los magistrados ${ }^{47}$.

Lo dicho no puede dejar de interpretarse como una forma típica de acumulación política. Si se lo piensa como una suerte de real politik judicial, estamos frente a redes de confianza que buscan sumar miembros y fortalecerse. Lo importante aquí es que, además, los entrevistados hacen lecturas políticas en donde prima una lógica de alianzas que tiene independencia de los dictados del ejecutivo y que expresan formas de funcionamiento que suponen ocupar espacios de poder por parte de los jueces como lo hace cualquier otro actor político en otras dependencias del Estado.

\section{Conclusiones}

En lo dicho resuena implícitamente la definición de Max Weber de política, en donde esta última no sería otra cosa que la aspiración a participar en el ejercicio del poder y/o en su distribución dentro del Estado por parte de los distintos grupos que lo componen. También, que una decisión es política cuando las condiciones de esta última se sostienen en la distribución, la conservación o la transferencia de este poder (Weber, 1979).

En este caso, esta definición de política, así como también los intereses de este tipo, excede la lógica partidaria que es donde habitualmente se escudan aquellos que buscan separar a los magistrados de cualquier práctica de estas características. En este sentido, si aceptamos que los jueces tienen intereses propios, independientes, en tér- 
minos relativos, de los otros poderes, toda la acción de los gestores e incluso de los jueces autogestivos muestran una aspiración a ocupar un lugar dentro del Estado y que esos lugares se disputan con los distintos grupos que buscan también ocupar ese espacio.

La pregunta que surge es cómo se logra ocupar los mencionados espacios. Un recurso para responder la interrogante planteada es recurrir al planteamiento antropológico asociado a la coexistencia de dos universos que regulan el funcionamiento del poder judicial, y que no deja de estar asociado al secreto y su vinculación con los gobiernos democráticos tan bien planteada por Norberto Bobbio (1985). De hecho, el autor italiano incluye dentro de este tema a los nombramientos de funcionarios en el seno del Estado (Bobbio, 1985).

Hay, entonces, un proceso informal que colabora con los nombramientos formales de funcionarios estatales; en este caso, de empleados, funcionarios y magistrados. Los mencionados nombramientos, en mayor o menor medida y en función del rango del nombramiento, suponen ocupar espacios para el ejercicio del poder dentro del Estado adscribiendo cada uno de los nombrados en los distintos grupos que lo componen.

En el caso de los nombramientos realizados por los mismos magistrados hacia al interior de los juzgados y vocalías, persiguen, dentro de la lógica weberiana, la distribución, la conservación o la transferencia del poder. En el caso de los nombramientos de los funcionarios, porque los jueces sitúan en la línea sucesoria a personas de su confianza para poder acceder a conducir el juzgado, como ese nombramiento aportan un vot más para elegirautoridades en las elecciones de la AMFJN.

En el caso de los concursos para magistrados, la situación plantea ciertos matices con relación a lo dicho en el párrafo anterior. Si bien es cierto que el nombramiento final de los magistrados depende del ejecutivo y del acuerdo de la comisión del senado, es cierto también que esa elección se realiza en función de una terna que se elabora en el Consejo de la Magistratura. Entonces, si el mencionado lobby de jueces en detrimento de la matrícula es exitoso, las ternas se terminan conformando por aquellos que responden a los distintos grupos de magistrados.

En este contexto, el patronage adquiere otra dimensión de análisis para el caso trabajado en este artículo. Ya no se trata solamente de aso- 
ciar nombramientos de magistrados en función de su adscripción partidaria, tal como lo propone un sector de la bibliografía anglosajona, sino de sumar al análisis los vínculos que poseen los candidatos con los distintos grupos de interés a los que pertenecen los magistrados.

Para poder llevar adelante este análisis es necesario replantear la categoría de familia judicial. Hay que dejar de verla como una forma de nepotismo que lleva a nombramientos internos dentro del PJN y empezar a pensarla como una dimensión más de los grupos que se disputan espacios de poder hacia su interior. Ya no es solo la familia de sangre, sino también la familia política.

Es la creación del Consejo de la Magistratura la que amplió tanto los escenarios de disputa como las redes de parentesco, dándole a la AMFJN un rol que antes no tenía. De hecho, no son pocos los jueces que hacen mención a este tema desde su propia perspectiva. Tal vez, la clave se encuentra en aquellos entrevistados que vivieron la transición de una Asociación sin Consejo a una Asociación con Consejo. Se dice de esta forma: "La lógica político institucional del Poder Judicial en la Argentina Pasó de una mutual a un sindicato"48; "dejó de ser el Jockey Club" ${ }^{49}$; y "llegó la disputa por el poder en serio" ${ }^{50}$.

En función de lo dicho, los procesos de negociación y disputa que se deprenden de la tabla de verdad, presentada en el apartado metodológico, están en este trabajo especialmente vinculados a los nombramientos: en primer lugar, tratando de mostrar que los magistrados tenían prácticas similares en sus propios lugares de trabajo, esto es, lo que en el esquema I se llamó administración del juzgado; en segundo lugar, describiendo cómo se expresaban los mencionados procesos en el Consejo, sobre todo en la tramitación de los concursos y la conformación de las ternas que son elevadas al ejecutivo; y, por último, cómo los procesos que llevan a los secretarios a subrogar juzgados vacantes pueden ser clasificados dentro de esta lógica.

Es interesante plantear también, y ese es el motivo por traje a colación a Norberto Bobbio, que es importante mantener esta cuestión en el ámbito del secreto para los magistrados. Pueden tener palabras

\footnotetext{
(Entrevista a Juez Federal, CABA).

(Entrevista a Camarista Federal, CABA).

(Entrevista a Juez Nacional, CABA).
} 
muy duras respecto del PJN y denunciar abiertamente su mal funcionamiento en términos jurisdiccionales, pero a la hora de hablar de cuestiones vinculadas a los concursos y los nombramientos piden que apague el grabador, lo que señala tanto la importancia que le dan a este tema como su necesidad de mantenerlo oculto.

Por último, las interrogantes que nos plantean los hallazgos preliminares, desarrollados en los párrafos anteriores y que puede servir como punto de partida para futuros trabajos, es cómo integrar en un análisis de estas características la dimensión asociada a los fallos judiciales y que está presente en los procesos de negociación y disputa presentados en el Esquema I. Aparecen entonces dos líneas de trabajo posibles y complementarias. En primer lugar, las decisiones jurisdiccionales en torno al régimen de jueces subrogantes y, en segundo lugar, las decisiones vinculadas al traspaso de la justicia nacional a la órbita del gobierno de la Ciudad Autónoma de Buenos Aires.

La primera de ellas nos permite analizar cómo se resuelve jurídicamente un problema político de los magistrados. Si ocupar espacios de poder es una acción política, que un secretario pueda subrogar un juzgado vacante debiese ser clasificado dentro de este tipo de acciones si, además, le agregamos que vota como magistrado en las elecciones para elegir representantes ante el consejo. La segunda nos permite analizar cómo repercute políticamente una decisión jurídica en donde la aparición de AJUFE puede ser analizada como una de las consecuencias lógicas de la discusión por el traspaso.

Ambas líneas permitirián complejizar el espacio de propiedades y la tabla de verdad presentados en el apartado metodológico. En este contexto, lo jurídico aparece como parte de la lógica de disputa política hacia el interior del PJN. Como dijo un entrevistado: "Para los enemigos el derecho y para los amigos la política" ${ }^{51}$.

\section{Referencias}

Ábalos, M. G. (2012). La autonomía presupuestaria del poder judicial: Una herramienta para garantizar la independencia judicial y la eficaz administración de justicia. Buenos Aires: Ad-Hoc.

${ }^{51}$ (Entrevista a Juez Federal, CABA). 
Acuña, C. (octubre, 2002). La dinámica político-institucional de la reforma judicial en Argentina. Trabajo presentado en VII Congreso Internacional del Centro Latinoamericano de Administración para el Desarrollo sobre la Reforma del Estado y de la Administración Pública, CLAD Lisboa, Portugal. Recuperado de http:// biblioteca.cejamericas.org/handle/2015/2406?show=full

Acuña, C., \& Alonso, G. (2003). La Reforma Judicial en América Latina: Un estudio político-institucional de las reformas judiciales en Argentina, Brasil, Chile y México (Trabajo de investigación). Recuperado de http://hdl.handle.net/10908/439

Aldrich, J. (1995). Why parties? The origin and transformation of party politics in America. Chicago: University Chicago Press.

Almeida, F. N. (2010). A nobreza togada: As elites jurídicas e a política da justiça no Brasil. (Tesis doctoral). Departamento de Ciência Política, Facultad de Filosofía, Letras e Ciencias Humanas, Universidad de São Paulo, Brasil.

Ansolabehere, K. (2005), Jueces, política y derecho. Particularidades y alcances de la judicialización de la política. Revista Isonomía, (22), pp. 39 - 62.

Arellano Ríos, A. (2008). Poder Judicial, ciencias sociales y consolidación democrática. Revista Espiral: Estudios sobre Estado y Sociedad, 14(43), pp. 123-150.

Basabe Serrano, S. (2011). Jueces sin toga: Políticas judiciales y toma de decisiones en el Tribunal Constitucional del Ecuador (19992007). Quito: FLACSO-Ecuador.

Bateson, G. (1998). Pasos hacia una ecología de la mente. Buenos Aires: Lohlé - Lumen.

Baum, L. (2017). Judges and their audiences. En L. Epstein \& S. Lindquist. (Eds.), The Oxford Handbook of U. S. Judicial Behavior. (pp. 343-360). Oxford: Oxford University Press.

Becker, H. (2009). Trucos del oficio. ¿Cómo conducir su investigación en ciencias sociales? Buenos Aires: Siglo XXI.

Bell,L.(2002). Senatorial Discourtesy: The Senate's Use of Delay to Shape the Federal Judiciary. Political Research Quarterly, 55(3), 589-607. Recuperado de http://dx.doi.org/10.2307/3088032

Bergalli, R. (1999). Hacia una cultura de la jurisdicción: Ideologías de jueces y fiscales en Argentina, Colombia, España e Italia. Buenos Aires: Ad-Hoc. 
Bielsa, R. \& Graña, E. (1996). Justicia y Estado. A propósito del Consejo de la Magistratura. Buenos Aires: Ediciones Ciudad Argentina.

Bill Chávez, R. (2007). The appointment and removal process for judges in Argentina: The role of judicial councils and impeachment juries in promoting judicial independence. Latin American Politics and Society, 49(2), 33-58. Recuperado de https://doi. org/10.1111/j.1548-2456.2007.tb00406.x

Black, R., Owens, R. \& Armaly, M. (2016). A well-traveled lot: A research note on judicial travel by U. S. Supreme Court Justices. Justice System Journal, 37(4), 367-384. Recuperado de http:// dx.doi.org/10.1080/0098261X.2016.1151387

Bobbio, N. (1986). La democracia y el poder invisible. En N. Bobbio (Ed.), El futuro de la democracia. (pp. 65-83). México D.F.: Fondo de Cultura Económica.

Böhmer, M. (2013). La lógica político institucional del Poder Judicial en la Argentina. En C. Acuña (Comp.), ¿Cuánto importan las instituciones? Gobierno, estado y actores en la política argentina. (pp. 157-208). Buenos Aires: Siglo XXI.

Bosch, B. (1998). En la Confederación Argentina, 1854-1861. Buenos Aires: EUDEBA.

Candioti, M. (2018. Un maldito derecho. Leyes, jueces y revolución en la Buenos Aires republicana, 1810-1830. Buenos Aires: Didot.

Código Civil y Comercial de la Nación (2014). Ley 1285/1958. Buenos Aires: DyD. Recuperado de http://servicios.infoleg.gob.ar/ infolegInternet/anexos/35000-39999/37915/texact.htm

D’Elia-Kueper, J. \& Segal, J. (2017). Ideology and Partisanship. En L. Epstein \& S. Lindquist (Eds.), The Oxford Handbook of U. S. Judicial Behavior. (pp. 303-319). Oxford: Oxford University Press.

Dezalay, Y. \& Garth, B. (2003). The internationalization of palace wars: Lawyers, economists, and the contest to transform Latin American States. Chicago: University of Chicago Press.

Donatello, L. \& Lorenc Valcarce, F. (2018). El ascenso a la elite judicial. Una reconstrucción de los orígenes y las trayectorias de jueces a partir de entrevistas biográficas. Revista Argentina de Sociología, 11(19-20), 6-29.

Donatello, L. \& Nachón Ramirez, M. (2019). Religion and traditional social elites: Argentinean federal judges, current practi- 
ces, beliefs and justifications ways. International Journal of Latin American Religions, 3, 139-155. Recuperado de http:// dx.doi.org/10.1007/s41603-019-00066-2

Durkheim, E. (1997). Las reglas del método sociológico. Madrid: Akal.

Eilbaum, L. (2008. Los "casos de policía" en la justicia federal en Buenos Aires: El pez por la boca muere. Buenos Aires: Antropofagia.

Frymer, P. \& Yoon, A. (2002). Political parties, representation, and federal safeguards. Northwestern University Law Review, 96(3), 977-1026. Recuperado de https://scholar.princeton.edu/ sites/default/files/pfrymer/files/northwestern_2002.pdf

Gargarella, R. (1996). La justicia frente al gobierno: Sobre el carácter contramayoritario del poder judicial. Barcelona: Ariel.

Garoupa, N. \& Guinsburg, T. (2009). Guarding the guardians: Judicial councils and judicial independence. The American Journal of Comparative Law, 57(1), 103-134. Recuperado de https:// doi.org/10.5131/ajcl.2008.0004

Gibson, J., Frendeis, J. P. \& Vertz, L. (1987). Party dynamics in the 1980's: Change in county organizational strength, 1980-1984. American Journal of Political Science, 33, 67-90. Recuperado de https://www.jstor.org/stable/2111254

Gillman, H. (2001). The votes that counted: How the court decided the 2000 presidential election. Chicago: Chicago University Press.

Guemureman, S. (2010). La cartografía moral de las prácticas judiciales en los tribunales de menores. Buenos Aires: Ediciones del Puerto.

Griffiths, J. A. G. (1977). The politics of the judiciary. Manchester: Manchester University Press.

Griffiths, J. A. G. (1993). Judicial politics since 1920: A chronicle. Oxford: Blackwell.

Hilbink, L. (2007). Judges beyond politics in democracy and dictatorship. Lessons from Chile. Nueva York: Cambridge University Press.

Howard, J. W. (1981). Courts of appeals in the federal judicial system. New Jersey: Princeton University Press.

Lanteri, A. L. (2011). Instituciones estatales y orden político. Diseño, prácticas y representaciones de la justicia federal en la “Confederación" (1854-1861). Revista Población \& Sociedad, 18(1), 49-78. Recuperado de http://ppct.caicyt.gov.ar/index. php/pys/article/view/12174 
Levaggi, A. (1997). Judicatura y política. La justicia federal en las provincias argentina (1863-1883). Buenos Aires: Ediciones Ciudad Argentina.

Llanos, M. \& Figueroa Schibber, C. (2007). Prestando acuerdo: El senado frente a los nombramientos del poder judicial en la Argentina democrática (1983-2006). GIGA Working Paper, (54), 5-39. Recuperado de https://core.ac.uk/download/ pdf/6862922.pdf

Martínez, M. J. (2007). La guerra de las fotocopias. Escritura y poder en las prácticas judiciales. En J. M. Palacios y M. Candioti (Eds.), Justicia, política y derechos en América Latina. (pp.203-218). Buenos Aires: Prometeo.

Nemacheck, C. (2017). Appointing supreme court justices. En L. Epstein \& S. Lindquist (Eds.), The Oxford Handbook of U. S. Judicial Behavior. (pp. 29-47). Oxford: Oxford University Press.

Oyhanarte, J. (1969) Poder político y cambio estructural en la Argentina. Buenos Aires: Paidós.

Palacio, J. M. (2018). La justicia peronista. La construcción de un nuevo orden legal en la Argentina. Buenos Aires: Siglo XXI.

Pásara, L. (2003). Justicia, régimen político y sociedad en América Latina. Política y Gobierno, 10(2), 413-426. Recuperado de http://www.politicaygobierno.cide.edu/index.php/pyg/article/viewFile/346/255

Pásara, L. (2015). Una reforma imposible: La justicia latinoamericana en el banquillo. México D.F: Instituto de Investigaciones Jurídicas, UNAM.

Perkins, J. \& Collins, Jr. P. (2017). Interest groups and the judiciary En L. Epstein \& S. Lindquist (Eds.), The Oxford Handbook of U. S. Judicial Behavior. (pp. 361-380). Oxford: Oxford University Press.

Pinello, D. (1999). Linking party to judicial ideology in American courts: A meta-analysis. The Justice System Journal, 20(3), 219-254. Recuperado de https://www.jstor.org/stable/27976992

Posdeley, C. (2018). El régimen jurídico de jueces subrogantes en el orden federal. Buenos Aires: Lajouane.

Rosenberg, G. (1991). The hollow hope: Can courts bring about social change? Chicago: University of Chicago Press.

Roth, L. (2007). Acerca de la independencia judicial en la argentina: La creación del Consejo de la Magistratura y su desempeño 
entre 1994 y 2006. Desarrollo Económico, 47(186), 285-318. Recuperado de https://www.jstor.org/stable/30037149

Sagüés, N. (1978). Mundo jurídico y mundo político. Buenos Aires: Depalma.

Sagüés, N. (2005). El tercer poder. Notas sobre el perfil político del poder judicial. Buenos Aires: LexisNexis.

Sarrabayrouse, M. J. (2004). La justicia penal y los universos coexistentes. Reglas universales y relaciones personales. En S. Tiscornia (Comp.), Burocracias y violencia: Estudios de antropología jurídica. (pp. 203-238). Buenos Aires: Antropofagia.

Sarrabayrouse, M. J. (2015). Desnaturalización de categorías: Independencia judicial y acceso a la justicia. Los avatares del proceso de democratización de la justicia en Argentina. Colombia Internacional, (84), 139-159. Recuperado de http://dx.doi. org/10.7440/colombiaint84.2015.05

Scheingold, S. (1974). The politics of rights: Lawers, public policy, and political change. New Haven: Yale University Press.

Scherer, N. (2017). Appointing federal judges. En L. Epstein \& S. Lindquist (Eds.), The Oxford Handbook of U. S. Judicial Behavior. (pp. 3-28). Oxford: Oxford University Press.

Smulovitz, C. (1995). El poder judicial en la nueva democracia argentina. El trabajoso parto de un actor. Ágora. Cuaderno de Estudios Políticos, (2), 85-106.

Tiscornia, S. (2007). Ordenes secretas, edictos y poder de policía. Usos y costumbres de los intermediarios en los márgenes del derecho. En J. M. Palacios \& M. Candioti (Eds.), Justicia, política y derechos en América Latina. (pp. 145 - 168). Buenos Aires: Prometeo.

Weber, M. (1979). La política como vocación. En M. Weber (Ed.), El político y el científico. (pp. 81-178). Madrid: Alianza.

Zaffaroni, R. (1994). Estructuras judiciales. Buenos Aires: Ediar.

Zimmermann, E. (2007). Centralización, justicia federal y construcción del estado en la organización nacional. Revista de Instituciones, Ideas y Mercados, (46), 265-292. 